\title{
Assessment of DNA methylation profiling and copy number variation as indications of clonal relationship in ipsilateral and contralateral breast cancers to distinguish recurrent breast cancer from a second primary tumour
}

Katie T. Huang ${ }^{1,2}$, Thomas Mikeska ${ }^{1,2,3}$, Jason Li4, Elena A. Takano ${ }^{1}$, Ewan K A Millar, ${ }^{5,6,7,8}$, Peter H. Graham, Samantha E. Boyle ${ }^{9}$, Ian G. Campbell ${ }^{2,9}$, Terence P. Speed ${ }^{10}$, Alexander Dobrovic ${ }^{1,2,3,11}$ and Stephen B. Fox ${ }^{1,2^{*}}$

\begin{abstract}
Background: Patients with breast cancer have an increased risk of developing subsequent breast cancers. It is important to distinguish whether these tumours are de novo or recurrences of the primary tumour in order to guide the appropriate therapy. Our aim was to investigate the use of DNA methylation profiling and array comparative genomic hybridization $(\mathrm{a} C \mathrm{GH})$ to determine whether the second tumour is clonally related to the first tumour.

Methods: Methylation-sensitive high-resolution melting was used to screen promoter methylation in a panel of 13 genes reported as methylated in breast cancer (RASSF1A, TWIST1, APC, WIF1, MGMT, MAL, CDH13, RARß, BRCA1, CDH1, CDKN2A, TP73, and GSTP1) in 29 tumour pairs (16 ipsilateral and 13 contralateral). Using the methylation profile of these genes, we employed a Bayesian and an empirical statistical approach to estimate clonal relationship. Copy number alterations were analysed using aCGH on the same set of tumour pairs.
\end{abstract}

Results: There is a higher probability of the second tumour being recurrent in ipsilateral tumours compared with contralateral tumours (38\% versus $8 \% ; p<0.05$ ) based on the methylation profile. Using previously reported recurrence rates as Bayesian prior probabilities, we classified $69 \%$ of ipsilateral and $15 \%$ of contralateral tumours as recurrent. The inferred clonal relationship results of the tumour pairs were generally concordant between methylation profiling and $\mathrm{aCGH}$.

Conclusion: Our results show that DNA methylation profiling as well as aCGH have potential as diagnostic tools in improving the clinical decisions to differentiate recurrences from a second de novo tumour.

Keywords: DNA methylation, Comparative genomic hybridisation, Ipsilateral, Contralateral, Breast

\footnotetext{
* Correspondence: Stephen.Fox@petermac.org

${ }^{1}$ Molecular Pathology Research and Development Laboratory, Department of

Pathology, Peter MacCallum Cancer Centre, St. Andrew's Place, East

Melbourne, VIC 3002, Australia

${ }^{2}$ Department of Pathology and Sir Peter MacCallum Department of

Oncology, University of Melbourne, Grattan Street, Parkville, VIC 3010,

Australia

Full list of author information is available at the end of the article
}

(C) 2015 Huang et al. Open Access This article is distributed under the terms of the Creative Commons Attribution 4.0 International License (http://creativecommons.org/licenses/by/4.0/), which permits unrestricted use, distribution, and reproduction in any medium, provided you give appropriate credit to the original author(s) and the source, provide a link to the Creative Commons license, and indicate if changes were made. The Creative Commons Public Domain Dedication waiver (http://creativecommons.org/publicdomain/zero/1.0/) applies to the data made available in this article, unless otherwise stated. 


\section{Background}

Patients with breast cancer are known to have a higher risk of developing a second breast tumour either in the affected (ipsilateral) or unaffected (contralateral) breast $[1,2]$. When the second tumour is detected, it is important to determine whether the tumour is a de novo (new primary) tumour or a recurrence of the first tumour [3, 4] as the tumour staging and management for the patient will be different [5]. A recurrent breast tumour is known to be a predictor of developing breast metastasis and is associated with poor survival [6,7], whereas a new primary may have a better outcome depending on the pathological features of the tumour [8].

Currently, histopathological features and clinical characteristics are most commonly used to determine the clonal origin of the tumours. These include histological type, degree of differentiation, presence of an in situ component, evidence for metastatic spread and the interval between tumour onsets [3]. However, tumours of distinct clonal origins may still have very similar histological features.

The use of molecular analysis can supply additional criteria to distinguish de novo second tumours from recurrent tumours. Goldstein et al. demonstrated that whereas six out of eight ipsilateral sample pairs (75\%) were clonally different using a loss of heterozygosity $(\mathrm{LOH})$ assay, the morphology of the tumour pairs was similar [9]. They also found that approximately $42 \%$ of sample pairs had discrepancies between histopathological classification and molecular classification using $\mathrm{LOH}$ patterns. Thus, using histopathological features and clinical characteristics alone may not correctly identify the relationship between de novo and recurrent breast cancer [9]. Recently, several other molecular methodologies have been assessed for their usefulness in determining the clonal relationship of the tumours. For example, microsatellite instability patterns [10-13], the pattern of X chromosome inactivation [14], and TP53 mutations [15] have been used. However, the best differentiation between de novo and recurrent tumours to date has been given by allelic imbalance profiles that result from $\mathrm{LOH}$ and tumour heteroploidy as measured by aCGH $[10,12,13,16]$.

DNA methylation changes are widespread in cancer and as methylation patterns are often clonally inherited [17], they can also be used to determine the clonal relationship of tumours. It is expected that tumours of the same clonal origin will have closely related DNA methylation patterns and profiles. In this study, we set out to compare DNA methylation profiling and $\mathrm{aCGH}$ as tools to distinguish between de novo and recurrent tumours.

\section{Methods}

\section{Sample collection and DNA preparation}

Formalin-fixed, paraffin-embedded (FFPE) samples for 16 pairs of ipsilateral and 13 pairs of contralateral breast cancers diagnosed from 1997 to 2007 were obtained from the St. George Hospital, Sydney, Australia. Ethics approval was granted by St. George Hospital Human Research Ethics Committee (07/60) with a waiver of informed consent to obtain archival samples. In addition our study complies with the current laws of Australia and ethics approval was obtained from the Peter MacCallum Cancer Centre Ethics Committee (03/90). Each pair included the primary tumour and the second tumour. The de-identified haematoxylin-eosin stained sections were reviewed by a pathologist and representative tumour areas were marked and needlemacrodissected and genomic DNA was extracted by 3 days incubation at $56{ }^{\circ} \mathrm{C}$ in buffer ATL (Qiagen, Hilden, Germany) with $20 \mathrm{mg} / \mu \mathrm{L}$ proteinase $\mathrm{K}$ (Qiagen) added daily, followed by QIAamp DNA Blood Mini Kit (Qiagen) spin columns according to the manufacturer's instructions.

\section{Bisulfite modification}

Genomic DNA (500 ng) was bisulfite modified using the MethylEasy $^{\mathrm{Tm}}$ Xceed (Human Genetic Signatures, North Ryde, Australia) according to the manufacturer's instructions. The modified DNA was eluted twice in $25 \mu \mathrm{L}$ of EB buffer. CpGenome ${ }^{\text {тм }}$ Universal Methylated DNA (Chemicon/Millipore, Billerica, MA) and peripheral blood mononuclear DNA were used as the methylated and unmethylated controls, respectively. DNA methylation standards $(5,10,25$ and $50 \%)$ made by diluting the fully methylated control in the unmethylated DNA were used as controls. Whole-genome amplification (WGA) was also used to make a fully unmethylated control and performed as described previously [18].

\section{Methylation-sensitive high-resolution melting (MS-HRM)}

MS-HRM was used to detect methylation in bisulfite modified samples according to the sequencedependent thermostability in which the level and presence of heterogeneous methylation can be detected [19, 20]. A panel of 13 genes that have been reported to be methylated in breast cancer (RASSF1A, TWIST1, CDH13, APC, MAL, GSTP1, WIF1, RAR $\beta$, BRCA1, CDKN2A, TP73, CDH1 and MGMT) was chosen for screening the breast carcinoma samples. $M L H 1$, which is not methylated in breast cancer, was included as a negative control for methylation. MS-HRM primers were used as previously described [21, 22] except for CDH13 and GSTP1. All MS-HRM assays were designed to amplify amplicon sizes around $100 \mathrm{bp}$ to enable amplification from the majority of FFPE samples. Primers were designed according to the principles described previously [23]. The CDH13 MS-HRM primers were 5'-TxTGGTTTTTACGGA 
AAATATGTTTAGTGTA-3' (forward) and 5'-AAT TCTCGACTACATTTTATCCGACTAAAA-3' (reverse). The 93 bp amplicon (GenBank AC092351 nucleotides 82660620-712) contains six CpGs. The GSTP1 MS-HRM primers were 5'-GGGGCGGGATTATTTTTATAAGG TT-3' (forward) and 5'-GAATTAACCCCATACTAA AAACTCTAAACC-3' (reverse). The $140 \mathrm{bp}$ amplicon (GenBank AP001184, nucleotides 67351239-337) contains 14 CpGs.

PCR amplification and high-resolution melting analysis were performed on the Rotor-Gene Q (Qiagen). PCR conditions for each gene are described in Table 1. PCR was performed using a final volume of $20 \mu \mathrm{L}$. The reaction mixture consisted of $1 \times \mathrm{PCR}$ buffer (Qiagen), $2.5-4.0 \mathrm{mmol} / \mathrm{L}$ of $\mathrm{MgCl}_{2}, 200 \mu \mathrm{mol} / \mathrm{L}$ of each dNTP, forward and reverse primers, $5 \mu \mathrm{mol} / \mathrm{L}$ of

Table 1 PCR amplification conditions for the MS-HRM assays

\begin{tabular}{|c|c|c|c|c|}
\hline Gene & $\begin{array}{l}\mathrm{MgCl}_{2} \\
\text { concentration } \\
\left(\mathrm{mmolL}^{-1}\right)\end{array}$ & $\begin{array}{l}\text { Primer } \\
\text { concentration } \\
\left(\mathrm{nmolL}^{-1}\right)\end{array}$ & $\begin{array}{l}\text { Cycling } \\
\text { time (sec) }\end{array}$ & $\begin{array}{l}\text { Annealing } \\
\text { temperature } \\
\left({ }^{\circ} \mathrm{C}\right)\end{array}$ \\
\hline \multirow[t]{2}{*}{$A P C$} & \multirow[t]{2}{*}{2.5} & $F-200$ & \multirow[t]{2}{*}{$10,15,20$} & \multirow[t]{2}{*}{58.5} \\
\hline & & $R-300$ & & \\
\hline \multirow[t]{2}{*}{$B R C A 1$} & \multirow[t]{2}{*}{4.0} & $F-250$ & \multirow[t]{2}{*}{$10,10,20$} & \multirow[t]{2}{*}{61.0} \\
\hline & & $R-250$ & & \\
\hline \multirow[t]{2}{*}{$\mathrm{CDH} 1$} & \multirow[t]{2}{*}{2.5} & $F-200$ & \multirow[t]{2}{*}{$10,10,20$} & \multirow[t]{2}{*}{63.5} \\
\hline & & $R-200$ & & \\
\hline \multirow[t]{2}{*}{$\mathrm{CDH} 13$} & \multirow[t]{2}{*}{3.0} & $F-300$ & \multirow[t]{2}{*}{$10,20,25$} & \multirow[t]{2}{*}{58.0} \\
\hline & & $R-400$ & & \\
\hline \multirow{2}{*}{$\begin{array}{l}\text { CDKN2A } \\
(P 16)\end{array}$} & \multirow[t]{2}{*}{2.5} & $F-300$ & \multirow[t]{2}{*}{$10,10,20$} & \multirow[t]{2}{*}{70.0} \\
\hline & & $R-200$ & & \\
\hline \multirow[t]{2}{*}{ GSTP1 } & \multirow[t]{2}{*}{2.5} & $F-200$ & \multirow[t]{2}{*}{$10,10,20$} & \multirow[t]{2}{*}{64.5} \\
\hline & & $R-200$ & & \\
\hline \multirow[t]{2}{*}{ MAL } & \multirow[t]{2}{*}{2.5} & $F-200$ & \multirow[t]{2}{*}{$10,10,20$} & \multirow[t]{2}{*}{59.0} \\
\hline & & $R-200$ & & \\
\hline \multirow[t]{2}{*}{ MGMT } & \multirow[t]{2}{*}{4.0} & $F-250$ & \multirow[t]{2}{*}{$10,20,20$} & \multirow[t]{2}{*}{60.0} \\
\hline & & $R-250$ & & \\
\hline MLH1 & 3.5 & $F-200$ & $10,15,20$ & 59.0 \\
\hline & & $R-300$ & & \\
\hline TP73 & 3.0 & $F-300$ & $10,15,20$ & 55.0 \\
\hline & & $R-200$ & & \\
\hline RARB & 3.0 & $F-200$ & $10,10,20$ & 66.0 \\
\hline & & $R-300$ & & \\
\hline RASSF1A & 3.0 & $F-300$ & $15,25,20$ & 65.0 \\
\hline & & $R-200$ & & \\
\hline TWIST1 & 2.5 & $F-200$ & $10,10,20$ & 52.0 \\
\hline & & $R-300$ & & \\
\hline WIF1 & 3.0 & $F-400$ & $10,20,25$ & 53.0 \\
\hline & & $R-400$ & & \\
\hline
\end{tabular}

SYTO9 intercalating dye (Invitrogen, Carlsbad, CA), 0.5U of HotStarTaq DNA polymerase (Qiagen) and $10 \mathrm{ng}$ of bisulfite modified DNA. HRM was performed directly after PCR amplification. HRM consisted of an inactivation step at $97{ }^{\circ} \mathrm{C}$ for $1 \mathrm{~min}$, rapid cooling to $72{ }^{\circ} \mathrm{C}$ (or $69{ }^{\circ} \mathrm{C}$ ), then melting of the sample from $72{ }^{\circ} \mathrm{C}$ to $95{ }^{\circ} \mathrm{C}$ with temperature rising by $0.2{ }^{\circ} \mathrm{C}$ per second and holding for $1 \mathrm{~s}$ after each stepwise increment for all assays. In each assay, fully methylated, WGA DNA (unmethylated), different DNA methylation percentage dilution standards and no template controls were also performed. All assays were performed in duplicate.

\section{Methylation scoring}

Methylation for each gene was considered positive when it was above $10 \%$. Setting a cut off point is important for methylation scoring as low-level endogenous methylation may also be found in normal breast tissue. This was observed in some patient matched normal breast tissues, where low levels of methylation (less than $10 \%$ ) can be detected for some genes in these matched normal breast tissues (KTH, TM, AD unpublished results). Samples giving non-reproducible melting profiles and late PCR amplification were scored as uninformative. Methylation was independently scored by KTH and TM, with a third opinion from $\mathrm{AD}$ where scoring was discrepant.

\section{Analysis of DNA methylation data}

The assumption was made that due to the clonal inheritance of methylation, clonally related tumours should have methylation patterns that closely resemble each other. Previous reports have shown that methylation levels increase during tumour progression in breast cancer (i.e., in situ carcinoma to invasive carcinoma) [24]. Therefore, the further assumption was made that an unmethylated marker in a primary tumour has a higher probability to be methylated in a clonally related second tumour than a methylated marker becoming unmethylated.

Log odds ratios were calculated for each pair of tumours as a measurement of likelihood of recurrence using methylation data. In the following formulas, $R$ stands for recurrence, i.e., the two given tumours come from the same origin; $\bar{R}$ for non-recurrence, i.e., different origins; $M$ represents methylated; and $\bar{M}$ represents unmethylated. $p_{i}$ represents the probability of gene $i$ being methylated, where the values of $p_{i}$ or each of the 13 genes have been estimated from the literature (see below). Thus, using $p_{i}$, the probabilities of a gene being A) methylated in both tumours, B) unmethylated in both tumours and $\mathrm{C}$ ) methylated in only one of the tumours can be calculated, conditional on recurrence/non-recurrence. 
Given non-recurrence, these probabilities are:

\begin{tabular}{lll}
\hline Non-recurrence & $\bar{M}$ (secondary) & $M$ (secondary) \\
$\bar{M}$ (primary) & $\left(1-p_{i}\right)^{2}$ & $p_{i}\left(1-p_{i}\right)$ \\
$M$ (primary) & $p_{i}\left(1-p_{i}\right)$ & $p_{i}^{2}$ \\
\hline
\end{tabular}

Given recurrence, the probability of losing methylation over the course of progression from primary to secondary tumour, $\gamma$ has been estimated from the aCGH data to be 0.05 . On the other hand, the probability of gaining methylation, which is expected to be higher as stated in our assumption above, is estimated to be $2 \gamma$

\begin{tabular}{lll}
\hline Recurrence & $\bar{M}$ (secondary) & $M($ secondary) \\
$\bar{M}$ (primary) & $(1-2 \gamma)\left(1-p_{i}\right)$ & $2 \gamma\left(1-p_{i}\right)$ \\
$M$ (primary) & $\gamma p_{i}$ & $(1-\gamma) p_{i}$ \\
\hline
\end{tabular}

These tables are used to calculate the probabilities of observing the methylation status of each gene as seen in the methylation data. For example, if primary tumour A is unmethylated and secondary tumour B is methylated in gene $i$, then, according to the recurrence and nonrecurrence probability tables respectively,

$\operatorname{Pr}\left(x_{i} \mid R\right)=2 \gamma\left(1-p_{i}\right)$ and $\operatorname{Pr}\left(x_{i} \mid \bar{R}\right)=p_{i}\left(1-p_{i}\right)$

where $x_{i}$ represents the observed methylation status of gene $i$ in the MS-HRM data.

The Log-Odds Ratios (LR) are then calculated by the formula described below.

$$
L R=\sum_{i=1}^{13} \log _{e} \frac{\operatorname{Pr}\left(x_{i} \mid R\right)}{\operatorname{Pr}\left(x_{i} \mid \bar{R}\right)}
$$

Two methods were then used to assess the LR values, and subsequently the likelihood of recurrence: an empirical approach and a Bayesian approach. The empirical approach unbiasedly utilises the methylation data to statistically assess clonal relationship by generating a null distribution of log-ratios representing the non-recurrence population, without making pre-assumptions about the likelihood of recurrence. However, since the strength of this approach is limited by the small sample size and the limited number of gene markers, more accurate classifications of de novo versus recurrence can be achieved by incorporating prior knowledge, hence the Bayesian approach.

\section{Method 1: Bayesian inference}

The key information required to calculate the likelihood is the probability of each of the 13 genes being methylated in tumours. The average methylation frequency of each gene in breast cancer was obtained from the literature [24-41]. The published results were reviewed and selected by two individuals together (KTH and TM) for the final decision (Additional file 1: Table S1). The aCGH data generated in the study was also used in the calculating the log odds ratios.

When the chance between recurrence and nonrecurrence is not 50/50, then Bayesian inference was used to calculate posterior LR, or PLR, based on the prior knowledge of the chance of recurrence/non-recurrence. Applying Bayes' theorem of conditional probability on the above LR formula, we get

$$
P L R=\log _{e} \frac{\operatorname{Pr}(R)}{\operatorname{Pr}(\bar{R})}+L R
$$

The prior probability of recurrence, i.e., $\operatorname{Pr}(R)$ were set at 0.75 for ipsilateral samples and 0.145 for contralateral samples. These values were obtained from literature that used molecular assays of aCGH, LOH and p53 mutations to differentiate recurrent and de novo tumours between the pair tumours $[9,12,15,16]$. The frequency of recurrent tumours found in ipsilateral tumour pairs was about $75 \%$ (ranged from 69-76\%), while the frequency of recurrent tumour found in contralateral tumour pairs was about $14.5 \%$ (averaged value of $14 \%$ and $15 \%$ ).

A sample can then be called recurrence or de novo depending on the PLR value: $P L R>0$ suggests recurrence, while $P L R<0$ suggests non-recurrence. These two inequalities are equivalent to $L R>-\log _{e} \frac{\operatorname{Pr}(R)}{\operatorname{Pr}(\bar{R})}$ and $L R<-\log _{e}$ $\frac{\operatorname{Pr}(R)}{\operatorname{Pr}(R)}$ respectively. Substituting in the probabilities of recurrences for ipsilateral samples gives $L R>-1.099$ and $L R<-$ 1.099. For contralateral samples, these are $L R>1.774$ and $L R<1.774$ respectively.

\section{Method 2: An empirical approach}

The methylation data was also used to obtain an empirical (i.e., prior knowledge was not used) null distribution of log ratios representing the non-recurrence population. Cross comparison between tumours from the 29 individuals gave us 3248 (pairing up each tumour with those from other individuals gives $2 \times 29 \times 2 \times 28=3248$ combinations) pairwise comparisons of non-recurrent cases. The LRs obtained from these comparisons form a null, or background, distribution from which $P$-values were calculated. The plot follows an approximately normally distribution (Additional file 2: Figure S1). P-values were calculated by counting the number of cases in the null with LRs larger than the LR of interest, and then dividing that number by the total number of null cases. The $P$-value cut-off for indicating the significance of recurrence was set at 0.05 in the study (i.e., a $P$-value $<0.05$ indicates the second tumour is likely to be clonally related to the first tumour). 


\section{Array comparative genomic hybridization (aCGH) data generation and analyses}

Genomic DNA (500 ng) from the same batch of tumour DNA as used in methylation profiling was analysed using the Agilent oligonucleotide array-bases CGH (4x microarray) following the manufacturer's instructions (Agilent Technologies, Santa Clara, CA). In brief, genomic DNA of samples and female reference DNA (a normal control DNA) (Promega, Madison, WI) were first fragmented for $30 \mathrm{~s}$ at $95{ }^{\circ} \mathrm{C}$ and $30 \mathrm{~min}$ at $95{ }^{\circ} \mathrm{C}$ respectively, and then the reference and sample DNA were labeled with ULS-Cy3 and ULS-Cy5 dye with the ratio $1 \mu \mathrm{L}$ per $1 \mu \mathrm{g}$ DNA, respectively. The non-reacted Cy-ULS dyes were removed using Agilent KREApure columns to reduce possible background noise for array screening. Optimal Cy5 degree of labeling (range between $0.75 \%$ and $2.5 \%$ ) with a $\mathrm{Cy} 3$ minus Cy5 range between $1 \%$ and $2 \%$ were used as a quality control guideline for sample labeling before hybridizing to the array. Samples and references DNA were hybridized on to the microarray at $65{ }^{\circ} \mathrm{C}$ for $40 \mathrm{~h}$, and then washed and scanned. aCGH result analyses was performed using the Partek $^{\bullet}$ Genomics Suite $^{\mathrm{TM}}$ version 6.03 (Partek Inc., St. Louis, MO).

\section{Statistical analysis}

Statistical analyses were performed using GraphPad Prism version 5.01 (GraphPad Software, San Diego, CA). Comparisons of age and tumour size between ipsilateral and contralateral groups were evaluated using the unpaired Student's $t$-test and nonparametric Mann-Whitney $U$ test, respectively. Fisher's exact test was used to examine the association between ipsilateral and contralateral groups with recurrent and de novo clonality. A two-tailed $p$-value of $<0.05$ was considered to be significant for each comparison.

\section{Results}

\section{Patient characteristics}

The clinical and pathological features of the patients in this study are summarised in Table 2. A trend was observed for patients with ipsilateral tumours to develop their primary tumours at an earlier median age than patients with contralateral tumours ( 54 vs. 59 years), although it was not significant at the $5 \%$ level $(P=0.08)$. The median age of onset for developing a second tumour was also earlier for ipsilateral patients compared with contralateral patients (59 vs. 68 years) $(P=0.07)$. However, the median time interval for the second tumours to develop was similar between ipsilateral patients (4 years; range, 0-14 years) and contralateral patients (5 years; range, $1-9$ years $)(P=0.60)$ after the initial breast tumour diagnosed.
Table 2 Clinicopathological features of the ipsilateral and contralateral breast cancers

\begin{tabular}{|c|c|c|}
\hline & $\begin{array}{l}\text { Ipsilateral } \\
(n=16)\end{array}$ & $\begin{array}{l}\text { Contralateral } \\
(n=13)\end{array}$ \\
\hline \multicolumn{3}{|l|}{ Age of onset (years) } \\
\hline \multicolumn{3}{|l|}{ Primary } \\
\hline Median & 54 & 59 \\
\hline Range & $37-75$ & $43-74$ \\
\hline$P$-value & & 0.082 \\
\hline \multicolumn{3}{|l|}{ Second tumour } \\
\hline Median & 59 & 68 \\
\hline Range & $40-82$ & $45-80$ \\
\hline$P$-value & & 0.070 \\
\hline \multicolumn{3}{|l|}{ Age interval (years) } \\
\hline Median & 4 & 5 \\
\hline Range & $0-14$ & $1-9$ \\
\hline$P$-value & & 0.604 \\
\hline \multicolumn{3}{|l|}{ Tumour size } \\
\hline \multicolumn{3}{|l|}{ Primary } \\
\hline Median (mm) & 17.8 & 17 \\
\hline Range (mm) & $6-50$ & $10-40$ \\
\hline$P$-value & & 0.711 \\
\hline \multicolumn{3}{|l|}{ Second tumour } \\
\hline Median (mm) & 13.5 & - \\
\hline Range (mm) & $0.3-75$ & - \\
\hline
\end{tabular}

${ }^{\mathrm{a}}$ Time interval between first and second tumour onset

DNA methylation patterns in ipsilateral and contralateral sample pairs

Methylation of 13 cancer related genes was assessed in 16 ipsilateral and 13 contralateral breast cancer pairs using MS-HRM (Table 3). In addition, promoter methylation of MLH1 was assessed and treated as a negative methylation control, as it is known to be unmethylated in breast carcinomas.

Eleven cancer related genes were found to have methylation (defined as more than $10 \%$ methylation) in at least some of the tumours: RASSF1A (64\%), TWIST1 (61\%), CDH13 (51\%), APC (50\%), MAL (35\%), GSTP1 (30 \%), WIF1 (26\%), RAR $\beta$ (19\%), BRCA1 (2 \%), CDKN2A (2\%) and TP73 (2\%). Two genes CDH1 and $M G M T$ were scored as unmethylated for all the samples in this study as either no methylation or very low-level methylation was detected. No promoter methylation of $M L H 1$ was found in any of the samples. Examples of the MS-HRM results are shown in Fig. 1.

\section{Determining clonal relationships using DNA methylation profiling}

DNA methylation patterns of the paired tumours were compared to assess the likelihood that the second 
Table 3 DNA methylation profile by MS-HRM analysis in (A) 16 ipsilateral and (B) 13 contralateral breast carcinomas

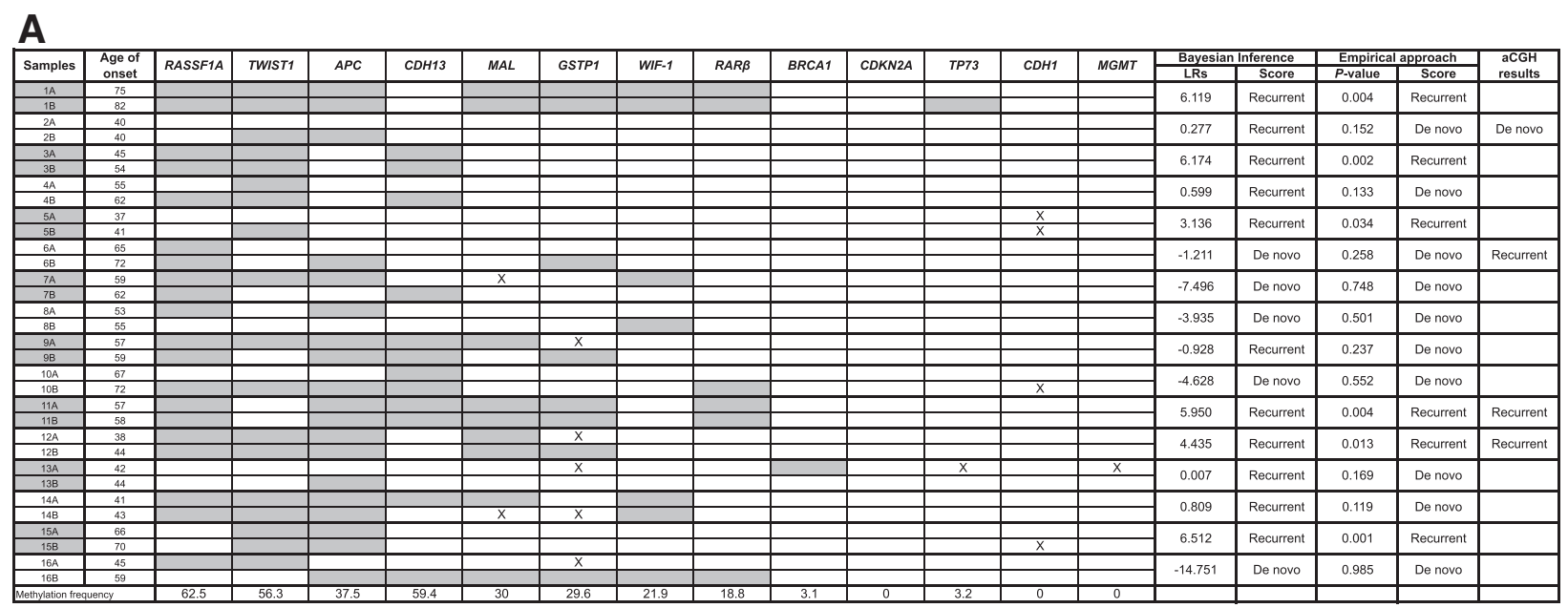

B

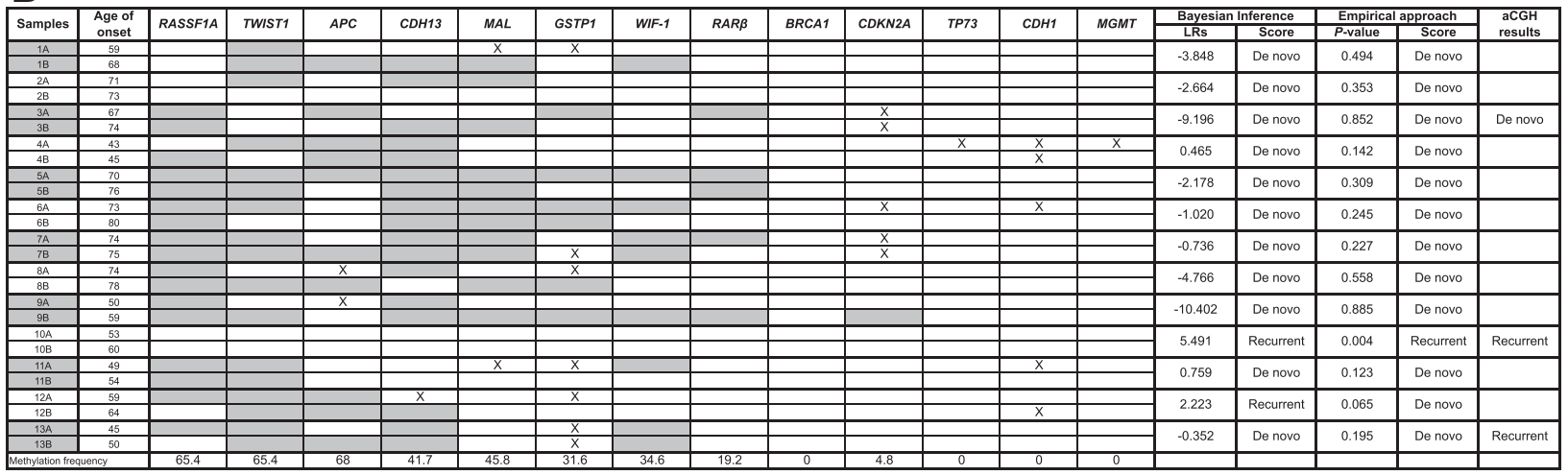

The methylation frequency of each gene and the age onset of each sample are included in the table. Results of tumour origin of the paired tumours that scored using MS-HRM and aCGH were stated on the left side of the table. Grey represents methylation and X represents samples that did not amplify

tumour had arisen from the first tumour. Some tumour pairs, in particular ipsilateral pairs, showed very similar DNA methylation patterns between the first and the second tumours, whereas others showed markedly different methylation patterns between the paired tumours. For example, ipsilateral tumour pair 1 showed highly similar methylation patterns, where all the genes that were methylated in the primary tumour were also methylated in the second tumour with additional methylation in TP73. On the other hand, contralateral pair 2 showed methylation of CDH13, MAL and TWIST1 in the first tumour but no methylation of any of the marker panel was found in the second tumour.

To objectively score whether both tumours are clonally related in origin using DNA methylation patterns between the paired tumours, log odds ratios were calculated as a measurement of likelihood of recurrence. An empirical approach was employed to assess the methylation data against an estimated null distribution without making a prior assumption on the likelihood of recurrence. Eight percent of contralateral tumours and $38 \%$ of ipsilateral tumours were called recurrent with a significance of $P<0.05$ using this approach. The much higher proportion of ipsilateral cases with recurrence is consistent with expectation, supporting the use of methylation data as a tool for assessing clonal relationship.

We also applied Bayesian inference to determine the clonal relationship between each pair of tumours based on their methylation patterns. Posterior log-odds ratios, indicating either positive or negative clonal relationships, were calculated for each tumour pair using previously obtained methylation frequency data for each of the genes (Additional file 1: Table S1). The prior probabilities of a tumour being recurrent for contralateral and ipsilateral pairs were estimated to be 0.145 and 0.75 respectively.

Using Bayesian inference, it was determined that there were eleven recurrent pairs (69\%) and five de novo pairs (31\%) in ipsilateral tumours, compared with two recurrent pairs (15\%) and eleven de novo pairs (85\%) in contralateral tumours (Table 4a). Using the empirical approach, it was determined that there were six recurrent pairs $(38 \%)$ and ten de novo pairs (62\%) in ipsilateral 

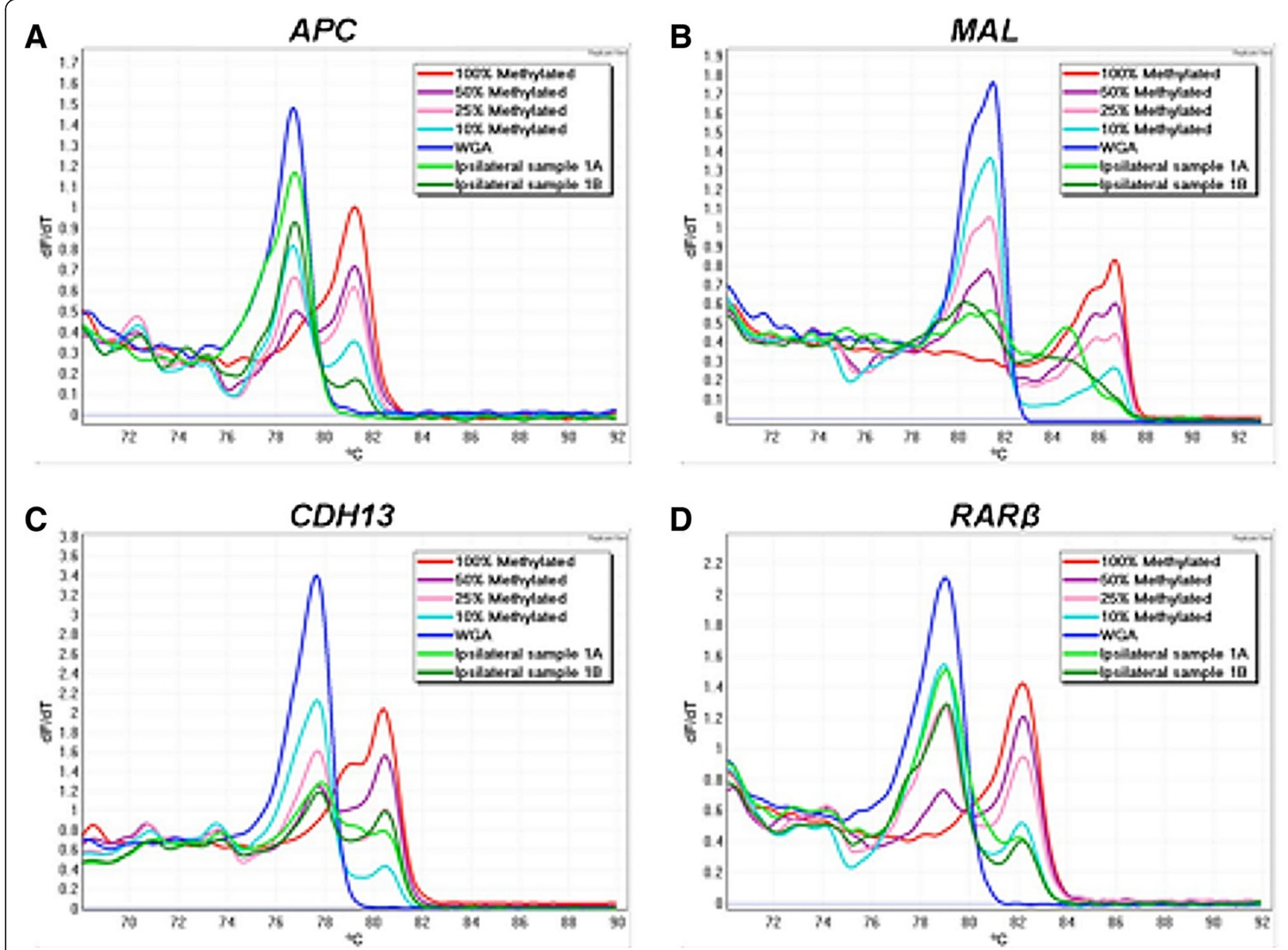

Fig. 1 Examples of MS-HRM analysis of a APC, b MAL, c CDH13 and $\mathbf{d} R A R \beta$ genes in ipsilateral sample 1. The figure shows negative first derivative ( $T_{m}$ ) melting curves of the MS-HRM profiles. MS-HRM differentiates the methylated DNA from the unmethylated DNA based on the sequence-dependent thermostability. Fully methylated samples melt later than the unmethylated WGA samples as there are cytosines retained in the sequence after bisulfite modification. Standards with different methylation levels (10\%, $25 \%$ and $50 \%$ ) were prepared by mixing the fully methylated DNA with fully unmethylated DNA. Ipsilateral sample 1A represents the first tumour and 1B represents the second tumour

tumours, compared with one recurrent pair $(8 \%)$ and twelve de novo pairs $(92 \%)$ in contralateral tumours (Table 4b). Although not all results analysed by both approaches were concordant (79.3\%), in both cases the results are consistent with the expectation that

Table 4 Summary of deduced clonal origins of ipsilateral and contralateral tumour pairs using (a) a Bayesian inference approach and (b) an empirical approach

\begin{tabular}{llll}
\hline & Recurrent & De novo & Total \\
\hline a & & & \\
\multicolumn{1}{l}{ Ipsilateral } & $11(69 \%)$ & $5(31 \%)$ & $16(100 \%)$ \\
Contralateral & $2(15 \%)$ & $11(85 \%)$ & $13(100 \%)$ \\
b & & & \\
Ipsilateral & $6(38 \%)$ & $10(62 \%)$ & $16(100 \%)$ \\
Contralateral & $1(8 \%)$ & $12(92 \%)$ & $13(100 \%)$ \\
\hline
\end{tabular}

ipsilateral tumours had a higher chance of being recurrent and contralateral tumours had a higher chance of being de novo.

\section{Comparison of genomic copy number in ipsilateral and contralateral tumour pairs}

Informative results using array comparative genomic hybridization $(\mathrm{aCGH})$ were obtained from 4 ipsilateral pairs and 3 contralateral pairs whereas the DNA quality from the remaining 17 sample pairs was too poor to achieve adequate labeling for array screening after at least two attempts. In general, the aCGH data from the second tumour was better quality with less noise than the data from the primary tumour consistent with the better quality of the DNA from the younger FFPE tumour block.

The copy number was compared between each tumour pair to determine the possible clonal 
relationship. Of the seven sample pairs, two of the second tumours were determined as de novo (one from ipsilateral pairs and one from contralateral pairs) and five of the second tumours were determined as recurrent (three from ipsilateral pairs and two from contralateral pairs). Array CGH results are summarised in Table 5.

Examples of aCGH results (ipsilateral pair 12 and contralateral pair 3) are shown in Fig. 2. In ipsilateral pair 12, the gains of chromosome 1q, part of 11q (including the cyclinD1 locus on11q13), 12p, part of 12q and 19 and losses of chromosome 6q, part of 11q, $12 \mathrm{q}$ and 13 were found in the primary tumour (Fig. 2a, b). These gains and losses were also found in the second tumour with the similar pattern or at the same position. Hence, the second tumour is highly likely to be recurrent from the primary. In contralateral pair 3, there were several gains and losses found in the primary tumour that was not found in the second tumour, such as gain of chromosome 11p and part of $17 \mathrm{q}$ and loss of chromosome 18. It is less likely for tumours of the same clonal origin to have different genomic copy number. Thus, the second tumour is likely to be a de novo tumour (Fig. 2c, d).

\section{Comparison between methylation profile and CGH microarray}

The best differentiation between de novo and recurrent tumours up to now has been given by allelic imbalance profiles. Therefore, the clonal origin results determined by aCGH was used to reflect the actual tumour origin of the tumour pairs in order to calculate the predictive values of sensitivity, specificity, positive predictive value and negative predictive value for methylation results scored by both algorithms (Table 6).

We compared the clonal results of the tumour pairs determined using methylation profiling and aCGH data. A discrepancy was seen in three out of seven tumour pairs when comparing aCGH prediction to the methylation profiling prediction using the Bayesian inference formula.

\section{Discussion}

Several types of molecular analyses have been previously used to assess the clonal relationships between ipsilateral and contralateral breast cancers. These include assays for genomic imbalance (by aCGH) and TP53 mutation screening $[3,10,15,16]$. We performed DNA methylation profiling of a set of genes commonly methylated in breast cancer to assess if this is of use to determine whether the first and the second tumour are clonally related.

It has been shown that individual breast cancers have a distinct profile of methylated genes [42]. Thus, we hypothesized that DNA methylation profiling either by itself or combined with genetic alterations using aCGH therefore might be a useful tool to distinguish between de novo and recurrent tumours.

The DNA methylation frequency of genes studied in our tumour cohort was compared with what has been reported in the literature for breast cancers (Additional file 1: Table S1). For example, RASSF1A, CDH13 and

Table 5 Gene copy number variation results from aCGH on seven sample pairs

\begin{tabular}{|c|c|c|c|c|c|}
\hline Sample & & Loss of chromosome & Gain of chromosome & Recurrent/De novo & Note \\
\hline \multirow[t]{2}{*}{ Ipsilateral 2} & First tumour & & & \multirow[t]{2}{*}{ Likely to be de novo } & \\
\hline & Second tumour & $2 p, 3 p$ (partial), & $7 q, 8 q, 10 p$ (partial), 19p & & \\
\hline \multirow[t]{2}{*}{ Ipsilateral 6} & First tumour & $3 p$ (partial) & $17 q$ (partial) & \multirow[t]{2}{*}{ Likely to be recurrent } & \multirow{2}{*}{$\begin{array}{l}\text { The second tumour still } \\
\text { retains the variation of the } \\
\text { primary tumour, especially } \\
\text { gain of } 17 q 12 \text { (Her } 2)\end{array}$} \\
\hline & Second tumour & $\begin{array}{l}3 p(\text { partial), 4q, } 8 p \\
9 p, 10 p, 11 q, 13,18\end{array}$ & $\begin{array}{l}1 \mathrm{q} \text { (partial), 12p, 14p, } \\
17 \mathrm{q} \text { (partial), 19p }\end{array}$ & & \\
\hline \multirow[t]{2}{*}{ |psilateral 11} & First tumour & & $5 q$ (partial), 8q (partial), 17q (partial) & \multirow[t]{2}{*}{ Recurrent } & \multirow{2}{*}{$\begin{array}{l}\text { Whole genome variation } \\
\text { of primary and second } \\
\text { tumour overlaid exactly }\end{array}$} \\
\hline & Second tumour & & $5 q$ (partial), 8q (partial), 17q (partial) & & \\
\hline \multirow[t]{2}{*}{ Ipsilateral 12} & First tumour & $6 \mathrm{q}, 11 \mathrm{q}, 12 \mathrm{q}, 13$ & $\begin{array}{l}1 \mathrm{q}, 11 p(\text { partial), } 12 \mathrm{p} \\
12 \mathrm{q} \text { (partial), } 19\end{array}$ & \multirow[t]{2}{*}{ Likely to be recurrent } & \multirow[t]{2}{*}{$\begin{array}{l}\text { Similar overall patterns in } \\
\text { chromosome } 11,12 \text { and } 19\end{array}$} \\
\hline & Second tumour & $\begin{array}{l}2 q(\text { partial), 3p (partial), } \\
4,6 q, 7 q \text { (partial), 11q, } \\
12 q, 13\end{array}$ & $\begin{array}{l}1 \mathrm{q}, 11 \mathrm{p} \text { (partial), } 12 \mathrm{p} \\
12 \mathrm{q}(\text { partial), 15, } 19\end{array}$ & & \\
\hline \multirow[t]{2}{*}{ Contralateral 3} & First tumour & $6 \mathrm{q}, 11 \mathrm{q}, 18$ & 1q, 11p, 17q (partial) & \multirow[t]{2}{*}{ Likely to be de novo } & \\
\hline & Second tumour & $6 q, 16 q, 22$ & $1 q, 16 p, X q$ & & \\
\hline \multirow[t]{2}{*}{ Contralateral 10} & First tumour & $3 p$ & $6 p, 8 q$ & \multirow[t]{2}{*}{ Likely to be recurrent } & \multirow{2}{*}{$\begin{array}{l}\text { Similar overall patterns, } \\
\text { especially in chromosome } 8 \text {, } \\
21 \text { and } 22\end{array}$} \\
\hline & Second tumour & & $6 p, 8 q$ & & \\
\hline \multirow[t]{2}{*}{ Contralateral 13} & First tumour & & $3 p$ (partial), 8q, 11q (partial) & \multirow[t]{2}{*}{ Likely to be recurrent } & \\
\hline & Second tumour & & $3 p$ (partial), 8q, 11q (partial) & & \\
\hline
\end{tabular}



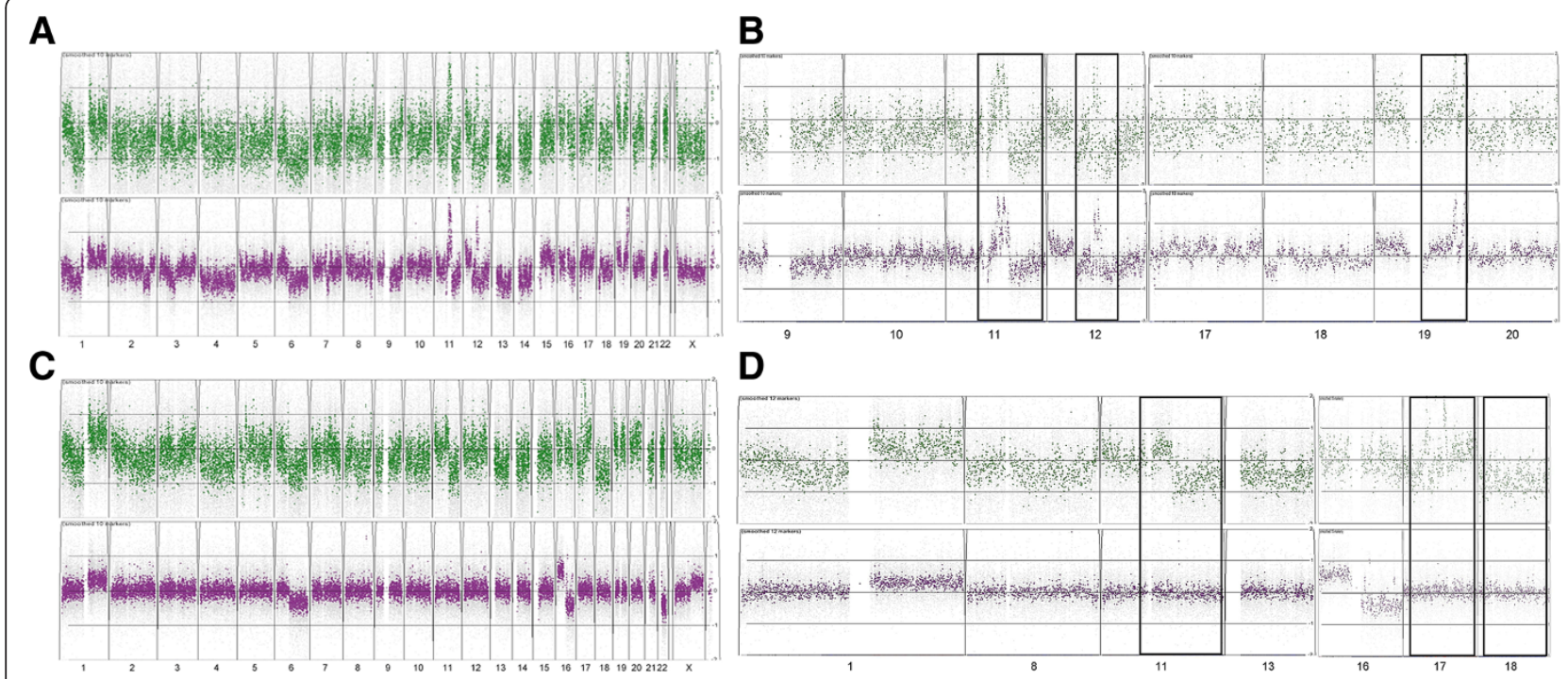

Fig. 2 Examples of genomic aCGH profiles of a recurrent ipsilateral pair 12 with a whole genome profile and $\mathbf{b}$ individual chromosomes of 9 , 10, $11,12,17,18,19$ and 20; and a de novo contralateral pair 3 with $\mathbf{c}$ whole genome profile and $\mathbf{d}$ individual chromosomes of 1, 8, 11, 13, 16, 17 and 18. Primary tumour (green) on top and the second tumour (purple) on bottom. Most informative areas were highlighted by the solid box

$R A R \beta$ have been reported to be frequently methylated in breast cancer (average frequency of $71 \%, 49 \%$ and $21 \%$ respectively, Additional file 1: Table S1), which is similar to our results of $64 \%, 51 \%$ and $19 \%$ methylation in both ipsilateral and contralateral pairs respectively. However discrepant values such as TWIST1 $61 \%$ vs $26 \%$, WIF1 $28 \%$ vs $65 \%$ and $C D H 10 \%$ vs $28 \%$ most likely represent variation in the region being examined and methodology. Interestingly, there was only one sample that was methylated for BRCA1 (2\%), a frequency about ten times less than what is typically identified in the literature $[26,43]$ that is likely due to bias from a relatively small series.

Although $C D H 1$ has been reported to be frequently methylated in breast tumours and suggested as a biomarker for breast cancer, we did not identify any methylation of $C D H 1$. Different methodologies have been used to detect the methylation status of $C D H 1$ in breast cancers and a wide range of methylation frequencies in breast cancers has been reported (range from 1 to $23 \%$ ).

Table 6 Predictive values of using methylation profiling with different algorithms to distinguish tumour origins $(n=7)$

\begin{tabular}{lllll}
\hline \multicolumn{4}{c}{ Methylation } & \\
\cline { 2 - 4 } & Recurrent & De novo & \\
\hline aCGH & Recurrent & 3 & 2 & $\mathrm{Sn}=0.60(3 / 5)$ \\
& De novo & 1 & 1 & $\mathrm{Sp}=0.50(1 / 2)$ \\
& & $\mathrm{PPV}=0.75(3 / 4)$ & $\mathrm{NPV}=0.33(1 / 3)$ & \\
\hline
\end{tabular}

Results were scored using Bayesian inference approach

$N P V$ negative predictive value, $P P V$ positive predictive value, $S n$ sensitivity, Sp specificity
However, our result was consistent with both our previous MS-HRM data (1\%: unpublished) and Feng et al. who employed bisulfite pyrosequencing [31] and reported methylation at low levels in both malignant and normal breast tissue.

The methods we have used eliminate the biases intrinsic to traditional ways of determining tumour origins, which often involve subjective input from a pathologist (operator) and which have shown to be inaccurate. However, the accuracy of our methods is dependent on a prior knowledge on methylation frequencies (in the case of Bayesian approach) or the number of samples from which a null distribution is estimated (empirical approach). Nevertheless, while both methods had similar NPV, the empirical approach showed a better representation and PPV suggesting is the better predictor for tumor relatedness based on methylation profiling. However it must be noted that this conclusion is based on a small number of tumors and gene markers.

Nonetheless, this study has demonstrated by methylation profiling, that a proportion of subsequent breast tumours share similar methylation profiles with the first tumour indicating that these tumours are likely to be clonally related. As also anticipated, ipsilateral tumours have a higher probability of being recurrent compared with contralateral tumours, which had a higher chance of being de novo tumours. These results are consistent with reports in the literature using different methodologies that ipsilateral breast cancers mostly arise from a single breast cancer whereas contralateral breast cancers frequently represent different primary breast cancers $[3,15,16]$. 
Based on previous studies, approximately $75 \%$ of second tumours are clonally related to the initial carcinoma in ipsilateral cases $[9,12,16]$, compared to only $\sim 15 \%$ of contralateral $[15,16]$. The frequency of recurrent and de novo tumours found in ipsilateral and contralateral cases reported in the literature are very close to the methylation results scored using the Bayesian inference approach in this paper. However, the recurrence rates called significant by our approach are lower than expected from the literature (15\% and $75 \%$ ).

Array $\mathrm{CGH}$ was used to validate the clonal predictions based on methylation but only a small number of samples were assessable by aCGH due to poor DNA quality. Nevertheless, informative aCGH results were obtained for seven sample pairs. In general, the later onset tumours had frequent additional genomic copy number alterations consistent with continued clonal evolution. Frequently altered genes in breast cancer can be useful as clinical markers, such as HER2 or CCND1, which allows the identification of the clonal relationship in a tumour pair. For example, gain of HER2 (17q12) was found in both primary and second tumours of ipsilateral pair 6, and gain of CCND1 (11q13) was found in both primary and second tumours of ipsilateral 12.

Genome-wide DNA copy number variation in tumours has been widely studied and used as a reliable tool to differentiate between tumours. However, the applicability of the technique to FFPE DNA is limited by DNA fragmentation, which can preclude generation of interpretable data. It is for this reason that we developed assays using MS-HRM that can be designed to meet the challenges associated with analysis of poor quality FFPE samples.

\section{Conclusions}

In summary, DNA methylation profiling using methodology compatible with degraded DNA has potential to be used as a diagnostic tool in improving the clinical decisions to differentiate recurrences from a second de novo tumour in FFPE samples.

\section{Additional files}

Additional file 1: Table S1. Comparison of DNA methylation frequency of genes screened in breast carcinomas with the methylation frequency in literature. (DOCX $100 \mathrm{~kb}$ )

Additional file 2: Figure S1. Normally distributed test statistics generated using empirical null distribution of LRs. $N=3248$ and bandwidth $=0.8926$. (TIFF $115 \mathrm{~kb})$

\section{Abbreviations}

aCGH: array comparative genomic hybridization; LOH: Loss of heterozygosity; FFPE: Formalin-fixed paraffin-embedded; WGA: Whole-genome amplification; MS-HRM: Methylation-sensitive high-resolution melting; PPV: Positive predictive value; NPV: Negative predictive value.

\section{Competing interests}

The authors declare that they have no competing interests.

\section{Authors' contributions}

$\mathrm{KTH}$ participated in the designing of DNA methylation and aCGH experiments, performed the experiments, DNA methylation and aCGH data analysis and interpretation, drafted and revised the manuscript. TM participated in analyzing and interpreting DNA methylation data. JL performed statistical analysis. EAT assisted with writing of the manuscript. Samples and clinicopathological data were collected by EKAM and PHG. SEB helped in performing aCGH experiment. IGC participated in analyzing and interpreting aCGH data. TPS contributed in statistical analysis. AD participated in the designing of the DNA methylation experiments and helped to analyse the data, and assisted with the writing of the manuscript. SBF conceptualised the study, contributed to manuscript writing and supervised the work. All authors have read and approved the final manuscript.

\section{Acknowledgements}

We wish to thank members of the Molecular Pathology Research and Development group in Peter MacCallum Cancer Centre for their help and support. We would like to thank Dr. Christoph Bock for helpful comments on analysis of the methylation results. This work was funded by grants from the Victorian Breast Cancer Research Consortium, Cancer Australia, the National Breast Cancer Foundation of Australia (Collaborative Research Program) and the Cancer Council of Victoria.

\section{Author details}

'Molecular Pathology Research and Development Laboratory, Department of Pathology, Peter MacCallum Cancer Centre, St. Andrew's Place, East Melbourne, VIC 3002, Australia. ${ }^{2}$ Department of Pathology and Sir Peter MacCallum Department of Oncology, University of Melbourne, Grattan Street, Parkville, VIC 3010, Australia. ${ }^{3}$ Translational Genomics and Epigenomics Laboratory, Olivia Newton-John Cancer Research Institute, Studley Road, Heidelberg, VIC 3084, Australia. ${ }^{4}$ Bioinformatics, Peter MacCallum Cancer Centre, St. Andrew's Place, East Melbourne, VIC 3002, Australia. ${ }^{5}$ South Eastern Area Laboratory Service (SEALS), St. George Hospital, Gary Street, Kogarah, NSW 2217, Australia. ${ }^{6}$ The Kinghorn Cancer Centre \& Garvan Institute of Medical Research, 384 Victoria Street, Darlinghurst, NSW 2010, Australia. ${ }^{7}$ School of Medicine and Health Sciences, University of Western Sydney, Narellan Road, Campbelltown, NSW 2560, Australia. ${ }^{8}$ Faculty of Medicine, University of NSW, High Street, Kensington, NSW 2052, Australia. ${ }^{9}$ VBCRC Cancer Genetics Laboratory, Peter MacCallum Cancer Centre, St. Andrew's Place, East Melbourne, VIC 3002, Australia. ${ }^{10}$ Bioinformatics Division, Walter and Eliza Hall Institute of Medical Research, 1G Royal Parade, Parkville, VIC 3052, Australia. ${ }^{11}$ School of Cancer Medicine, La Trobe University, Bundoora, VIC 3084, Australia.

Received: 12 December 2014 Accepted: 1 October 2015

Published online: 09 October 2015

\section{References}

1. Chen $Y$, Thompson W, Semenciw R, Mao Y. Epidemiology of contralateral breast cancer. Cancer Epidemiol Biomarkers Prev. 1999;8:855-61.

2. Goldstein NS, Kestin L, Vicini F. Factors associated with ipsilateral breast failure and distant metastases in patients with invasive breast carcinoma treated with breast-conserving therapy. A clinicopathologic study of 607 neoplasms from 583 patients. Am J Clin Pathol. 2003;120:500-27.

3. Imyanitov EN, Hanson KP. Molecular pathogenesis of bilateral breast cancer. Cancer Lett. 2003;191:1-7.

4. Ziogas D, Roukos DH. Genetics and personal genomics for personalized breast cancer surgery: progress and challenges in research and clinical practice. Ann Surg Oncol. 2009;16:1771-82

5. Hameed O, Pfeifer JD. Classifying "recurrent" breast cancer: lost heterozygosity found. Am J Clin Pathol. 2005;123:641-3.

6. Haffty BG, Reiss M, Beinfield M, Fischer D, Ward B, McKhann C. Ipsilateral breast tumor recurrence as a predictor of distant disease: implications for systemic therapy at the time of local relapse. J Clin Oncol. 1996;14:52-7.

7. Elkhuizen PH, van de Vijver MJ, Hermans J, Zonderland HM, van de Velde CJ, Leer JW. Local recurrence after breast-conserving therapy for invasive breast cancer: high incidence in young patients and association with poor survival. Int J Radiat Oncol Biol Phys. 1998;40:859-67. 
8. Huang E, Buchholz TA, Meric F, Krishnamurthy S, Mirza NQ, Ames FC, et al. Classifying local disease recurrences after breast conservation therapy based on location and histology: new primary tumors have more favorable outcomes than true local disease recurrences. Cancer. 2002;95:2059-67.

9. Goldstein NS, Vicini FA, Hunter S, Odish E, Forbes S, Kraus D, et al. Molecular clonality determination of ipsilateral recurrence of invasive breast carcinomas after breast-conserving therapy: comparison with clinical and biologic factors. Am J Clin Pathol. 2005;123:679-89.

10. Saad RS, Denning KL, Finkelstein SD, Liu Y, Pereira TC, Lin X, et al. Diagnostic and prognostic utility of molecular markers in synchronous bilateral breast carcinoma. Mod Pathol. 2008;21:1200-7.

11. Goldstein NS, Vicini FA, Hunter S, Odish E, Forbes S, Kestin LL. Molecular clonality relationships in initial carcinomas, ipsilateral breast failures, and distant metastases in patients treated with breast-conserving therapy: evidence suggesting that some distant metastases are derived from ipsilateral breast failures and that metastases can metastasize. Am J Clin Pathol. 2005;124:49-57.

12. Vicini FA, Antonucci JV, Goldstein N, Wallace M, Kestin L, Krauss D, et al. The use of molecular assays to establish definitively the clonality of ipsilateral breast tumor recurrences and patterns of in-breast failure in patients with early-stage breast cancer treated with breast-conserving therapy. Cancer. 2007;109:1264-72.

13. Kuligina E, Grigoriev MY, Suspitsin EN, Buslov KG, Zaitseva OA, Yatsuk OS, et al. Microsatellite instability analysis of bilateral breast tumors suggests treatment-related origin of some contralateral malignancies. J Cancer Res Clin Oncol. 2007;133:57-64.

14. Banelli B, Casciano I, Di Vinci A, Gatteschi B, Levaggi A, Carli F, et al. Pathological and molecular characteristics distinguishing contralateral metastatic from new primary breast cancer. Ann Oncol. 2009.

15. Janschek E, Kandioler-Eckersberger D, Ludwig C, Kappel S, Wolf B, Taucher S, et al. Contralateral breast cancer: molecular differentiation between metastasis and second primary cancer. Breast Cancer Res Treat. 2001;67:1-8.

16. Teixeira MR, Ribeiro FR, Torres L, Pandis N, Andersen JA, Lothe RA, et al. Assessment of clonal relationships in ipsilateral and bilateral multiple breast carcinomas by comparative genomic hybridisation and hierarchical clustering analysis. Br J Cancer. 2004;91:775-82.

17. Herman JG, Baylin SB. Mechanisms of disease: Gene silencing in cancer in association with promoter hypermethylation. New Engl J Med. 2003;349:2042-54.

18. Kristensen LS, Mikeska T, Krypuy M, Dobrovic A. Sensitive Melting Analysis after Real Time-Methylation Specific PCR (SMART-MSP): high-throughput and probefree quantitative DNA methylation detection. Nucleic Acids Res. 2008;36.

19. Wojdacz TK, Dobrovic A. Methylation-sensitive high resolution melting (MS-HRM): a new approach for sensitive and high-throughput assessment of methylation. Nucleic Acids Res. 2007;35

20. Candiloro IL, Mikeska T, Hokland P, Dobrovic A. Rapid analysis of heterogeneously methylated DNA using digital methylation-sensitive high resolution melting: application to the CDKN2B (p15) gene. Epigenetics Chromatin. 2008;1(1):7.

21. Huang KT, Dobrovic A, Yan M, Karim RZ, Lee CS, Lakhani SR, et al. DNA methylation profiling of phyllodes and fibroadenoma tumours of the breast. Breast Cancer Res Treat. 2010;124(2):555-65.

22. Wong EM, Southey MC, Fox SB, Brown MA, Dowty JG, Jenkins MA, et al. Constitutional methylation of the BRCA1 promoter is specifically associated with BRCA1 mutation-associated pathology in early-onset breast cancer. Cancer Prev Res (Phila). 2011;4:23-33.

23. Wojdacz TK, Hansen LL, Dobrovic A. A new approach to primer design for the control of PCR bias in methylation studies. BMC Res Notes. 2008;1:54.

24. Pasquali L, Bedeir A, Ringquist S, Styche A, Bhargava R, Trucco G. Quantification of $\mathrm{CpG}$ island methylation in progressive breast lesions from normal to invasive carcinoma. Cancer Lett. 2007;257:136-44.

25. Ai L, Tao Q, Zhong S, Fields CR, Kim WJ, Lee MW, et al. Inactivation of Wnt inhibitory factor-1 (WIF1) expression by epigenetic silencing is a common event in breast cancer. Carcinogenesis. 2006;27:1341-8.

26. Bianco T, Chenevix-Trench G, Walsh DC, Cooper JE, Dobrovic A. Tumour-specific distribution of BRCA1 promoter region methylation supports a pathogenetic role in breast and ovarian cancer. Carcinogenesis. 2000;21:147-51.

27. Cho YH, Yazici H, Wu HC, Terry MB, Gonzalez K, Qu M, et al. Aberrant promoter hypermethylation and genomic hypomethylation in tumor, adjacent normal tissues and blood from breast cancer patients. Anticancer Res. 2010;30:2489-96.
28. Dobrovic A, Simpfendorfer D. Methylation of the BRCA1 Gene in Sporadic Breast Cancer. Cancer Res. 1997:57:3347-50.

29. Esteller M, Corn PG, Baylin SB, Herman JG. A gene hypermethylation profile of human cancer. Cancer Res. 2001:61:3225-9.

30. Esteller M, Silva JM, Dominguez G, Bonilla F, Matias-Guiu X, Lerma E, et al. Promoter hypermethylation and BRCA1 inactivation in sporadic breast and ovarian tumors. J Natl Cancer Inst. 2000;92:564-9.

31. Feng $W$, Shen $L$, Wen S, Rosen DG, Jelinek J, Hu X, et al. Correlation between $\mathrm{CpG}$ methylation profiles and hormone receptor status in breast cancers. Breast Cancer Res. 2007;9:R57.

32. Gort EH, Suijkerbuijk KP, Roothaan SM, Raman V, Vooijs M, van der Wall E, et al. Methylation of the TWIST1 promoter, TWIST1 mRNA levels, and immunohistochemical expression of TWIST1 in breast cancer. Cancer Epidemiol Biomarkers Prev. 2008;17:3325-30

33. Horne HN, Lee PS, Murphy SK, Alonso MA, Olson Jr JA, Marks JR. Inactivation of the MAL gene in breast cancer is a common event that predicts benefit from adjuvant chemotherapy. Mol Cancer Res. 2009;7:199-209.

34. Jin Z, Tamura G, Tsuchiya T, Sakata K, Kashiwaba M, Osakabe M, et al Adenomatous polyposis coli (APC) gene promoter hypermethylation in primary breast cancers. Br J Cancer. 2001;85:69-73.

35. Prasad CP, Mirza S, Sharma G, Prashad R, DattaGupta S, Rath G, et al. Epigenetic alterations of $\mathrm{CDH} 1$ and $\mathrm{APC}$ genes: relationship with activation of Wnt/beta-catenin pathway in invasive ductal carcinoma of breast. Life Sci. 2008:83:318-25.

36. Ronneberg JA, Tost J, Solvang HK, Alnaes Gl, Johansen FE, Brendeford EM, et al. GSTP1 promoter haplotypes affect DNA methylation levels and promoter activity in breast carcinomas. Cancer Res. 2008;68:5562-71.

37. Sharma G, Mirza S, Yang YH, Parshad R, Hazrah P, Datta Gupta S, et al. Prognostic relevance of promoter hypermethylation of multiple genes in breast cancer patients. Cell Oncol. 2009;31:487-500.

38. Toyooka KO, Toyooka S, Virmani AK, Sathyanarayana UG, Euhus DM, Gilcrease $M$, et al. Loss of expression and aberrant methylation of the $\mathrm{CDH13}$ (H-cadherin) gene in breast and lung carcinomas. Cancer Res. 2001;61:4556-60.

39. Veeck J, Wild PJ, Fuchs T, Schuffler PJ, Hartmann A, Knuchel R, et al. Prognostic relevance of Wnt-inhibitory factor-1 (WIF1) and Dickkopf-3 (DKK3) promoter methylation in human breast cancer. BMC Cancer. 2009:9:217.

40. Wei M, Grushko TA, Dignam J, Hagos F, Nanda R, Sveen L, et al. BRCA1 promoter methylation in sporadic breast cancer is associated with reduced BRCA1 copy number and chromosome 17 aneusomy. Cancer Res. 2005;65:10692-9.

41. Wei M, Xu J, Dignam J, Nanda R, Sveen L, Fackenthal J, et al. Estrogen receptor alpha, BRCA1, and FANCF promoter methylation occur in distinct subsets of sporadic breast cancers. Breast Cancer Res Treat. 2008;111:113-20.

42. Van der Auwera I, Yu W, Suo L, Van Neste L, van Dam P, Van Marck EA, et al. Array-based DNA methylation profiling for breast cancer subtype discrimination. PLoS One. 2010;5, e12616.

43. Catteau A, Harris WH, Xu CF, Solomon E. Methylation of the BRCA1 promoter region in sporadic breast and ovarian cancer: correlation with disease characteristics. Oncogene. 1999;18:1957-65.

\section{Submit your next manuscript to BioMed Central and take full advantage of:}

- Convenient online submission

- Thorough peer review

- No space constraints or color figure charges

- Immediate publication on acceptance

- Inclusion in PubMed, CAS, Scopus and Google Scholar

- Research which is freely available for redistribution 